\title{
2.
}

PHYSICAL EDUCATION, FITNESS AND SPORTS

\section{Predictors of Motivation to Coach in High School Students and Adult Coaches}

Received 07 August 2019

Accepted $05^{\text {th }}$ October 2019

www.ijpefs.com

\section{Merry J. Sleigh a, Donna Webster Nelson a, , Alyssa M. Nelson a, Darren R. Ritzer a}

a Department of Psychology, Winthrop University, Rock Hill, SC 29733, United States.

*Corresponding Author Email: nelsond@winthrop.edu

Abstract: We conducted two studies to investigate predictors of coaching motivation. In Study One, we focused on variables linked to coaching motivation and burnout in adult sports coaches. We examined high school extracurricular experiences, and coaching engagement. Positive interpersonal events experienced during high school predicted coaching motivation and a motivation. Positive interpersonal and performance events in high school predicted feelings of reduced accomplishment, while negative interpersonal and performance events in high school predicted physical exhaustion. Two aspects of coaching engagement, vigor and absorption predicted coaching motivation. Thus, coaches' motivation was predicted by both high school and current coaching events. In Study Two, we examined whether the same high school events predicted a desire to coach in recent high school graduates. Participants retrospectively reported participation in high school sports or heavy investment in alternate activities (e.g., marching band). For both groups, identification with the activity and dedication to the activity predicted a desire to coach. A desire to coach was not predicted by high school extracurricular events. Our findings indicate that high school experiences exerted differential effects on recent graduates versus adult coaches in terms of attitudes toward coaching.

Key Words: Coaches, Coaching Motivation, Desire to Coach, Burnout, Engagement, High school athletes

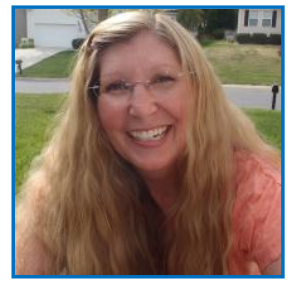

Dr. Sleigh is a professor in the Department of Psychology at Winthrop University. She received her doctorate in developmental psychology from Virginia Tech in 1996 and did a postdoctoral fellowship at Indiana University. She directed the Psychology Honors Program at George Mason University prior to joining the faculty at Winthrop in 2003. Sleigh has taught a range of classes but most regularly Research Methods, Biopsychology, and Learning. Her research interests focus on neonatal development, adolescent experiences, teaching effectiveness, and helping undergraduates gain research experience. She has received numerous awards for her teaching and mentoring of undergraduate students.

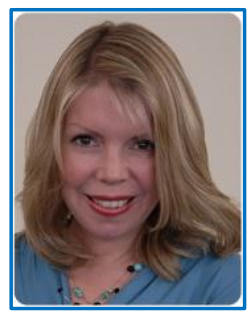

Dr. Nelson received her Ph.D. in social psychology from the University of Maryland. Her research focus while a graduate student involved social cognition, personality, and group processes. After receiving her degrees, she taught for three years in the Psychology Department at the University of Florida before joining the Psychology Department at Winthrop University. As a faculty member at Winthrop, Nelson teaches several courses, including general psychology, social psychology, theories of personality, and positive psychology. She has published numerous scholarly articles in the areas of social cognition, interpersonal processes and positive emotion. Her most current research investigates motivation and emotion of athletes and coaches in competitive sports.

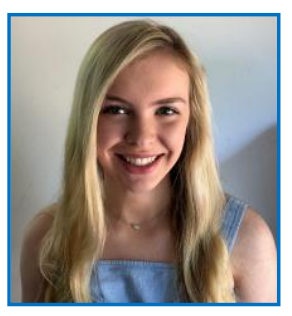

Ms. Nelson is an undergraduate psychology student at Duke University. She has been involved in competitive sports for many years as both an athlete and a coach. Her research interests center on well-being of adolescents, burnout in competitive sports and coach motivation. She recently co-authored a publication examining predictors of well-being and emotional burnout in high school athletes. She has also delivered numerous conference presentations focused on emotion and motivation in athletes and coaches.

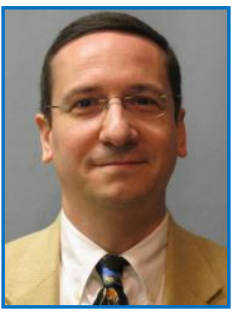

Dr. Ritzer is an associate professor in the Department of Psychology at Winthrop. He received his doctorate in industrial/organizational psychology from Virginia Tech. Prior to joining the faculty at Winthrop in 2003, Ritzer was an active duty officer in the U.S. Army. Dr. 


\section{Merry J. Sleigh et al.,/2019}

Ritzer regularly teaches a wide range of courses including Introductory Psychology, Statistics and Industrial/Organizational Psychology. His research interests focus on stress and performance, and he is heavily involved in supporting undergraduate research.

\section{Introduction}

Coaches play an instrumental role in athlete outcomes, both within and beyond the context of their sport [1]. Supportive coaches are more likely to have athletes with increased motivation, greater sport commitment, enhanced performance, and healthier lifestyles [2-6]. Reynders et al. (2019) conducted a study where they specifically trained youth sport coaches to offer autonomy support to their athletes and subsequently found greater athlete motivation and engagement under trained, versus untrained, coaches [7].

Because of the influential role of coaches, researchers have investigated factors that predict a lack of coaching persistence. For example, Lee and Chelladurai (2018) [8] found that intention to quit was related to higher burnout and lower job satisfaction, while Short, Short, and Haugen (2015) reported that low efficacy coaches experienced more stress and vulnerability to burnout. Coach burnout has also been linked to coaches failing to have the same goals as, or poor relationships with, their athletes $[9,10]$. In a longitudinal study, coaches who quit felt less satisfied and useful, and experienced higher a motivation, or a lack of motivation, than those who persisted [11].

The flip side of dropping out is staying engaged, and similar factors emerge as important. Alcarez et al. (2015) found that coaches were more motivated when they felt their players were motivated and when they had opportunities for professional development [12]. In a recent study, Grassmann, Schermuly, and Wach (2019) examined factors related to coaches' psychological and physical well-being and found that positive relationships with and higher goal attainment by their clients predicted coaches' feeling less negative, more competent, and less stressed [13]. Rocchi and Pelletier (2017) argued that coaches' motivation and well-being is impacted by a large number of contextual factors including their athletes, colleagues, and family [14].
Despite these reported studies, limited research attention has been devoted to coach motivation, an oversight that has importance as motivation impacts coach behavior [15]. For example, Rocchi, Pelletier, and Couture (2013) found that motivated coaches, compared to less motivated coaches, utilized more positive autonomy-supportive strategies, those in which coaches provide opportunities for their athletes to form their own goals and decisions [16]. Jowett (2008) examined both athletes and coaches, finding that intrinsically motivated coaches had athletes who were more satisfied with the coach-athlete relationship [17]. Given the notable impact coaches exert on the lives of athletes, more research is needed to understand variables that inspire a desire to coach.

\section{Study 1: Coaches' Motivation to Coach and Investment in Coaching}

Affective Events Theory argues that positive or negative events evoke emotional responses that influence individuals' attitudes or actions [18]. Consistent with this theory, recent research indicates that daily positive and negative events predict engagement and burnout of workers and athletes $[19,20]$. Nelson et al. (2019) examined the impact of daily events on high school athletes and non-athletes' extracurricular participation, focusing specifically on positive performance, positive interpersonal, negative performance, and negative interpersonal events [20]. The researchers found that positive performance events predicted extracurricular activity engagement in both groups. However, burnout was related to both performance and interpersonal events for athletes and only related to performance events in non-athletes. In other words, daily high school events predicted factors related to motivation. Thus, one avenue of exploration for coach motivation is their experiences of daily events.

Clopton (2015) examined student-athletes' intention to coach and concluded that potential 


\section{Merry J. Sleigh et al.,/2019}

coaches have formed perceptions of barriers, average number of years coaching was $5.27(S D=$ outcomes, and self-efficacy prior to becoming a coach 4.77). All participation was voluntary, and [21]. In other words, some aspects of the coaching participants were offered the incentive of being in a experience, particularly the desire to coach, precede drawing for one of two $\$ 50$ gift cards.

coaching itself. With this in mind, we explored the extent to which positive and negative experiences during high school extracurricular activities predicted burnout and motivation to coach in adult sports coaches. We also explored how their current experiences, such as coaching engagement, influenced coaches' motivation. We hypothesized that:

1. Positive interpersonal and performance extracurricular events in high school would predict higher levels of coaching motivation.

2. Negative interpersonal and performance extracurricular events would predict higher levels of coaching amotivation and burnout.

3. Current engagement with coaching would predict higher levels of motivation.

\subsubsection{Materials \& Procedures}

Coaches were recruited via social media platforms and personal contact and invited to participate in an online survey. The protocol received Institutional Review Board approval. First, we asked participants to indicate the importance of coaching in their life, the extent to which their identity was based on being a coach, and their ability as a coach compared to other coaches; these responses were made on 5-point Likert scales. Participants were asked to rank five factors (self-esteem, group cohesion, winning, improvement/growth, and fun) with 1 representing the factor that they perceived was most important to them as a coach and 5 representing the factor that was least important to them.

Participants then responded to the 22-item

4. Because motivation of athletes impacts coach motivation, compared to recreational coaches, professional coaches would report higher levels of engagement and motivation [12].

\subsection{Method}

\subsubsection{Participants}

Participants were 50 recreational to professional adult sports coaches, with a mean age of $34.83(S D=10.65)$. Twenty-six were women, 22 were men, and the remainder chose not to identify their gender. Forty-two were Caucasian, 6 were African American, and the remainder chose not to identify an ethnic identity. Twenty-eight participants coached on recreational leagues, 17 on elite competition or travel teams, and the remainder coached at the professional level. The coaches represented a range of sports: baseball $(n=3)$, basketball ( $n=3)$, cheerleading ( $n=2)$, cross-country $(n=5)$, football $(n=2)$, gymnastics $(n=1)$, lacrosse $(n=2)$, soccer $(n=14)$, softball $(n=1)$, swimming ( $n$ $=1)$, tennis $(n=1)$, and volleyball $(n=7)$. The

Coach Motivation Scale [15]. This scale had six subscales: intrinsic, integrated, identified, introjected, external, and amotivation; all items started with the stem, "Why do you coach your sport?" A sample intrinsic item was "because I enjoy the interaction I have with athletes." A sample integrated item was "because coaching is fundamental to who I am." A sample identified item was "because it contributes to my development as a person." A sample introjected item was "because if I quit it would mean I'd failed." A sample external item is "to be respected by others." Amotivation represented a feeling that one's coaching efforts were useless or wasted. A sample amotivation item was "I often think my coaching efforts are a waste of time." Responses were made on a 7-point scale where 1 represented "Not at all true" and 7 represented "Very true." The published alpha reliabilities are .87 for intrinsic, .80 for integrated, .77 identified, .71 for introjected, .81 for external, and .79 for amotivation [15]. We achieved alpha reliabilities of .81 for intrinsic, .87 for integrated, .90 for identified, .66 for introjected, .84 for external, and .83 for amotivation. This scale was tested with multiple models for the sub-scales. For our study, we 


\section{Merry J. Sleigh et al.,/2019}

combined the five sub-scales related to motivation original composite scale is .88. The published (intrinsic, integrated, identified, introjected, external) reliability for the subscales is .84 for RA, .88 for PE to create an overall motivation score for each and .87 for D [23]. We computed a reliability alpha of participant; this scale had an alpha reliability of .88.

Participants also responded to the 12-item Sport Engagement Scale, which assesses three aspects of engagement: vigor, absorption, and dedication [22]. On the original scale, the statements refer to a sport activity. We modified the scale by changing the sport activity reference to that of coaching. For example, "I am persistent in my sport activity" was modified to become "I am persistent in my coaching." An example of a modified item assessing vigor was "I was able to coach for long periods of time." An example of an item assessing dedication was "I was enthusiastic about coaching." An example of an item assessing absorption was "Time flew when I was coaching." Participants responded on a 7-point scale where 1 represented "Hardly ever" and 7 represented "Almost always." The scale has a published reliability alpha of .90 , with sub-scale reliabilities of .75 for vigor, .75 for dedication, and .74 for absorption [22]. We computed an overall alpha reliability of .89 , and computed .79 for vigor, .88 for dedication, and .71 for absorption.

Participants responded to a modified version of the 15-item Athlete Burnout Questionnaire, divided into three sub-scales to assess different aspects of burnout: reduced sense of accomplishment over time (RA), emotional/physical exhaustion (PE), and devaluation of the sport [23]. The original scale measures the level of physical and emotional tiredness that an athlete experiences. We modified the wording to refer to coaching. For example, one item measuring exhaustion "I feel physically worn out from swimming" was modified to "I feel physically worn out from coaching." A sample item for reduced sense of accomplishment was "I am not performing up to my ability in coaching," and a sample item for devaluation was "The effort I spend coaching would be better spent doing other things." Participants responded on a 7-point scale where 1 represented "Hardly ever" and 7 represented "Almost always." The published alpha for the .88 for our modified scale. For the sub-scales, we computed .81 for RA, .96 for PE, and .73 for D.

We then asked participants to reflect on their high school experiences and the coaching/mentoring they received. Those who invested in a high school sport focused on that sport (89\%) while the remainder focused on an alternate activity that involved a coach or mentor (e.g., marching band). All participants responded to 51 items that assessed the extent of positive and negative interpersonal and performance events experienced during extracurricular participation [20]. A sample negative performance item was "I felt unmotivated during training/practice." A sample positive performance item was "I exceeded my personal best at a critical time." A sample negative interpersonal item was "My coach expected too much from me." A sample positive interpersonal item was "My teammates and I supported each other." Participants responded on a 6-point Likert scale where 1 represented "Never" and 6 represented "Very Often." Published alpha reliabilities for the sub-scales range from .90 to .93, and we computed alpha reliabilities of .91 for positive interpersonal, .92 for negative interpersonal, .87 for positive performance, and .85 for negative performance. Last, participants responded to demographic questions to assess age, gender, and race.

\subsection{Results}

We attempted to predict the overall motivation score using hierarchical regressions and variables that preceded the coaching itself. We included positive interpersonal, positive performance, negative interpersonal and negative performance. An overall motivation to coach was predicted only by positive interpersonal events $(t=-$ $2.91, p=.006), F(4,36)=3.07, p=.028, R^{2}=.26$. See Table 1. 
Table 1. Summary of Hierarchical Regression Analysis for Variables Predicting Motivation to Coach for Coaches

\begin{tabular}{|c|c|c|c|c|c|c|}
\hline Variable & $\beta$ & $t$ & $p$ & $\mathbf{R}$ & $\mathbf{R}^{2}$ & $\Delta \mathrm{R}^{2}$ \\
\hline Step 1 & & & & .380 & .144 & .144 \\
\hline Positive interpersonal & -.380 & -2.56 & .014 & & & \\
\hline Step 2 & & & & .435 & .189 & .045 \\
\hline Positive interpersonal & -.497 & -2.98 & .005 & & & \\
\hline Positive performance & .243 & 1.45 & .154 & & & \\
\hline Step 3 & & & & .445 & .198 & .008 \\
\hline Positive interpersonal & -.557 & -2.87 & .007 & & & \\
\hline Positive performance & .217 & 1.25 & .219 & & & \\
\hline Negative interpersonal & -.120 & -.625 & .536 & & & \\
\hline Step 4 & & & & .505 & .255 & .057 \\
\hline Positive interpersonal & -.552 & -2.91 & .006 & & & \\
\hline Positive performance & .219 & 1.29 & .204 & & & \\
\hline Negative interpersonal & -.427 & -1.62 & .114 & & & \\
\hline Negative performance & .392 & 1.66 & .106 & & & \\
\hline
\end{tabular}

Table 2. Summary of Hierarchical Regression Analysis for Variables Predicting Amotivation for Coaches

\begin{tabular}{|c|c|c|c|c|c|c|}
\hline Variable & $\boldsymbol{\beta}$ & $\boldsymbol{t}$ & $p$ & $\mathbf{R}$ & $\mathbf{R}^{2}$ & $\Delta \mathbf{R}^{2}$ \\
\hline Step 1 & & & & .305 & .093 & .093 \\
\hline Positive interpersonal & .305 & 2.00 & .050 & & & \\
\hline Step 2 & & & & .340 & .115 & .022 \\
\hline Positive interpersonal & .387 & 2.22 & .032 & & & \\
\hline Positive performance & -.169 & -.972 & .337 & & & \\
\hline Step 3 & & & & .342 & .117 & .002 \\
\hline Positive interpersonal & .415 & 2.04 & .049 & & & \\
\hline Positive performance & -.158 & -.868 & .391 & & & \\
\hline Negative interpersonal & .054 & .271 & .788 & & & \\
\hline Step 4 & & & & .465 & .216 & .099 \\
\hline Positive interpersonal & .422 & 2.17 & .037 & & & \\
\hline Positive performance & -.155 & -.894 & .378 & & & \\
\hline Negative interpersonal & -.351 & -1.30 & .203 & & & \\
\hline
\end{tabular}


Table 3. Summary of Hierarchical Regression Analysis for Variables Predicting Burnout RA for Coaches

\begin{tabular}{|c|c|c|c|c|c|c|}
\hline Variable & $\beta$ & $t$ & $p$ & $\mathbf{R}$ & $\mathbf{R}^{2}$ & $\Delta \mathbf{R}^{2}$ \\
\hline Step 1 & & & & .169 & .029 & .029 \\
\hline Positive interpersonal & .169 & 1.07 & .291 & & & \\
\hline Step 2 & & & & .438 & .192 & .163 \\
\hline Positive interpersonal & .392 & 2.35 & .024 & & & \\
\hline Positive performance & -.462 & -2.77 & .009 & & & \\
\hline Step 3 & & & & .454 & .206 & .014 \\
\hline Positive interpersonal & .470 & 2.44 & .020 & & & \\
\hline Positive performance & -.429 & -2.49 & .018 & & & \\
\hline Negative interpersonal & .155 & .812 & .422 & & & \\
\hline Step 4 & & & & .486 & .236 & .030 \\
\hline Positive interpersonal & .474 & 2.47 & .018 & & & \\
\hline Positive performance & -.427 & -2.49 & .017 & & & \\
\hline Negative interpersonal & -.070 & -.262 & .795 & & & \\
\hline Negative performance & .287 & 1.20 & .239 & & & \\
\hline
\end{tabular}

Table 4. Summary of Hierarchical Regression Analysis for Variables Predicting Burnout-PE for Coaches

\begin{tabular}{|c|c|c|c|c|c|c|}
\hline Variable & $\boldsymbol{\beta}$ & $t$ & $p$ & $\mathbf{R}$ & $\mathbf{R}^{2}$ & $\Delta \mathrm{R}^{2}$ \\
\hline$\underline{\text { Step } 1}$ & & & & .021 & .000 & .000 \\
\hline Positive interpersonal & .021 & .132 & .895 & & & \\
\hline Step 2 & & & & .024 & .001 & .000 \\
\hline$\underline{\text { Positive interpersonal }}$ & .028 & .081 & .936 & & & \\
\hline Positive performance & .025 & .069 & .945 & & & \\
\hline$\underline{\text { Step } 3}$ & & & & .038 & .001 & .001 \\
\hline$\underline{\text { Positive interpersonal }}$ & .064 & .159 & .874 & & & \\
\hline$\underline{\text { Positive performance }}$ & .041 & .109 & .914 & & & \\
\hline Negative interpersonal & .054 & .180 & .858 & & & \\
\hline$\underline{\text { Step } 4}$ & & & & .500 & .250 & .248 \\
\hline Positive interpersonal & .086 & .241 & .811 & & & \\
\hline Positive performance & .049 & .148 & .883 & & & \\
\hline Negative interpersonal & -.844 & $\underline{-2.28}$ & .028 & & & \\
\hline
\end{tabular}




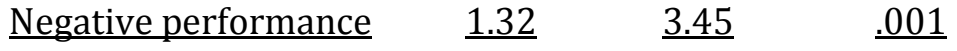

Table 5. Summary of Hierarchical Regression Analysis for Engagement Subscales Predicting Motivation to Coach for Coaches

\begin{tabular}{|c|c|c|c|c|c|c|}
\hline Variable & $\boldsymbol{\beta}$ & $t$ & $p$ & $\mathbf{R}$ & $\mathbf{R}^{2}$ & $\Delta \mathrm{R}^{2}$ \\
\hline Step 1 & & & & .392 & .154 & .154 \\
\hline Dedication & .392 & 2.79 & .008 & & & \\
\hline Step 2 & & & & .550 & .303 & .149 \\
\hline Dedication & -.161 & -.715 & .479 & & & \\
\hline Vigor & .674 & 3.00 & .005 & & & \\
\hline Step 3 & & & & .651 & .424 & .121 \\
\hline Dedication & -.372 & -1.70 & .097 & & & \\
\hline Vigor & .574 & 2.74 & .009 & & & \\
\hline Absorption & .459 & 2.94 & .005 & & & \\
\hline
\end{tabular}

Using the same four predictors, an attitude of coaching amotivation was also predicted by positive interpersonal events $(t=2.00, p=.05), F(1,39)=$ $4.01, p=.05, R^{2}=.09$. See Table 2 .

Next, we investigated the three sub-scales of burnout independently as they assessed unique aspects (physical exhaustion, reduced accomplishment, and devaluation). Burnout D was not predicted by high school experiences; however, burnout RA was predicted by positive performance events $(t=-2.49, p=.02)$ and positive interpersonal events $(t=2.47, p=.02), F(4,36)=2.79, p=.04, R^{2}=$ .24. See Table 3 .

Burnout PE was predicted by negative interpersonal ( $t=-2.28, p=.03)$ and negative performance events $(t=3.45, p=.001), F(4,36)=$ $3.00, p=.03, R^{2}=.25$. See Table 4 .

We also tested the three sub-scales of coaching engagement (dedication, vigor, and absorption) as predictors for coaching motivation with a hierarchical regression. Coaching motivation was predicted by vigor ( $t=2.74, p=.009$ ) and absorption $(t=2.94, p=.005), F(3,41)=10.07, p<$ $.001, R^{2}=.42$. See Table 5 .
We examined relations among variables using correlations. The higher the overall coaching motivation, the more coaches based their identity on coaching, $[r(48)=.75, p<.001]$ and the more important coaching was to them $[r(48)=.60, p<$ .001]. Coaches who agreed that their own high school coach had a positive impact on their lives were the most engaged $[r(46)=.34, p=.02]$. The more coaches reported that their identity was linked to their sport, the higher their overall engagement scores $[r(47)=$ $.45, p<.01]$, and the more they emphasized improvement in their athletes $[r(48)=-.36, p=.01]$, but the more burnout PE they experienced, $[r(45)=$ $.47, p<.01]$

Overall, when we asked coaches to rank factors most important to their coaching, improvement and growth was their top priority $(M=$ $1.65, S D=.93)$ followed by athlete cohesion $(M=$ $2.74, S D=1.24)$, fun $(M=2.74, S D=1.29)$, selfesteem building $(M=3.53, S D=1.27)$, and winning $(M=4.0, S D=1.18)$. The coaches who were least likely to emphasize fun as a goal were the ones who reported that coaching was more important to them $[r(47)=.44, p=.002]$ and had the highest burn-out physical exhaustion $[r(44)=.34, p=.023]$ 


\section{Merry J. Sleigh et al.,/2019}

We compared our male and female adult coaches using an independent $t$-test. There were no differences in their motivation to coach, how much they based their identity on coaching, or their high school experiences. Compared to female coaches, male coaches rated their coaching ability higher $[t(47)=2.17, p=.035]$, rated winning as more important $[t(45)=-2.34, p=.024]$, and rated athlete cohesion as less important $[t(45)=2.10, p=.04]$.

We compared our recreational coaches $(n=$ $28)$ to our elite or professional coaches $(n=22)$ using an independent $t$-test. Compared to recreational coaches, professional coaches had higher overall engagement scores $[t(43)=-2.23, p=.031]$, higher overall motivation $[t(46)=-4.13, p<.001]$, and higher burnout PE scores, [t(43) $=-2.13, p=.039]$. Professional coaches also felt coaching was more important to them $[t(46)=-3.24, p=.002]$, based more of their identity on coaching $[t(46)=-4.09, p<$ $.001]$, emphasized winning more $[t(45)=.37, p=$ $.001]$, and rated their high school extracurricular activity more positively [t(42) $=-2.09, p=.043]$. Supporting these outcomes, coaches who agreed more that they were motivated to "develop their own child's athletic skills" were less focused on their athletes' winning $[r(47)=.33, p=.03]$ and had lower engagement scores $[r(45)=-.35, p=.018]$.

\subsection{Discussion}

We hypothesized that both positive interpersonal and performance high school events would increase coaching motivation, while negative high school events would increase a motivation and burnout; these predications were partially supported. Coaching outcomes were linked to high school events; however, not in the exact pattern we predicted. Positive interpersonal events emerged as a particularly influential factor, predicting an overall motivation to coach. Many of our positive interpersonal items related to the coach-athlete relationship, and previous researchers have clearly documented the impact of these relationships on athlete motivation and satisfaction [24, 25, 26]. Thus, our adult coaches may have experienced meaningful relationships with their own coaches in high school and were revealing a desire to pay forward the mentoring they received. In fact, our data revealed that the most engaged coaches reported having a high school coach who had a positive impact on their lives, and previous researchers have found that coaches frequently cite their best learning experiences to be time with their own mentors [27, 28].

This other-focused motivation, driven by past experiences, may also explain why positive interpersonal events also made coaches vulnerable to amotivation. Our coaches, who experienced positive relationships with their teammates and coaches in high school, may have felt pressure to recreate those experiences for their own athletes. The pressure, or failure to meet their own expectations, could account for the lack of motivation we found. Indeed, Westfall et al. (2018) found that poor interpersonal relationships between coaches and athletes directly contributed to coach burnout [10].

Burnout RA was predicted by coaches' recollections of positive high school performance and interpersonal events, while burnout PE was predicted by recollections of negative interpersonal and performance events. In other words, social relationships and personal performance were both high school factors that predicted feelings of exhaustion and reduced investment during coaching. Coaches whose high school extracurricular experiences are salient and emotional may be especially sensitive to the experiences of their own young athletes. For some coaches, this awareness may result in working too hard. Others may feel frustrated by the inability to maximize their athlete's potential because of their own inadequacies, or because of limitations in their athletes. Previous researchers have shown that coaches' amotivation was higher when their players exhibited low motivation or when they felt less useful as a coach $[11,12]$.

We also investigated coaches' current experiences to assess their impact on coaching motivation. The more coaches' own identity was tied to being a coach, the more overall engagement and motivation they felt, but the more burnout PE they experienced. When identity is linked to accomplishments, failure becomes personal, and 


\section{Merry J. Sleigh et al.,/2019}

thus, it is likely these coaches were tiring themselves by exerting tremendous energy and self-directed pressure. Burnout potentially affected their athletes in addition to the coaches, as coaches higher in burnout PE were less likely to prioritize fun as a goal for their athletes. Previous researchers have demonstrated that fun is a critical reason students participate in school sports [29].

We also hypothesized that current engagement with coaching would predict higher levels of motivation and found support. Vigor and absorption, both elements of engagement that relate to energetic effort and focus during coaching, predicted motivation. Taken collectively, our findings suggest that coaches' attitudes toward coaching are influenced by past events as well as current events. This data aligns with Clopton's (2015) argument that adults enter coaching with predetermined attitudes and expectations, and our data suggest that these expectations may drive actual coaching outcomes [21].

We also found that the level of coaching, recreational versus professional, emerged as a more influential variable than did gender and found support for our hypothesis. Compared to elite and professional coaches, recreational coaches were less motivated and engaged, findings which may explain the previously documented difficulty in retaining volunteer coaches [30]. However, on a positive note, the recreational coaches experienced less burnoutPE than did the professional coaches. These results likely reflect the differential level of investment and winning percentages required of recreational, versus more elite, coaches.

\section{Study 2: High School Graduates' Desire to Coach}

Because high school experiences predicted adult coaches' desire to mentor, we investigated whether high school graduates who had more recently encountered the same positive and negative extracurricular events would already have opinions regarding their desire to coach. Young adults who are connected with and invested in their high school activities would be most likely to want to continue their participation in those activities, and thus may be considering coaching as one option. This might be particularly true of athletes who have the most personal connection with and knowledge of coaching. Fasting, Sand and Knorre (2013) questioned Norwegian and Czch female athletes and found that two thirds of them planned to coach in the future [31]. In this light, we hypothesized that

1. Positive interpersonal high school extracurricular experiences would predict a stronger desire to coach in the future.

2. A stronger identification with and engagement in their high school extracurricular activities would predict a stronger desire to coach in the future.

3. Compared to non-athletes, athletes would express a stronger desire to coach in the future.

\subsection{Method}

\subsubsection{Participants}

Participants $(n=106)$ were recruited through undergraduate classrooms on a university campus and offered partial course credit for participation. We targeted freshmen-level classrooms in an attempt to maximize the number of young adults who had recently completed high school. Twenty-three participants identified as men, 82 identified as women, and one person identified as transgender. The mean age was $20.46(S D=1.96)$. Sixty-nine participants reported as White/Caucasian, 30 as Black/African American, and the remainder reported other ethnic identities.

Fifty-nine participants reported sports participation during high school, and the remainder reported no sports participation during high school. The most common sports activities were soccer $(n=$ $11)$, track $(n=9)$, softball $(n=7)$, basketball $(n=6)$, and tennis $(n=6)$. Other sports included football, cheerleading, golf, gymnastics, ice skating, lacrosse, swimming, karate, and equestrian. The most common non-sports activities reported were marching band $(n=11)$, orchestra/music $(n=10)$, theatre $(n=5)$, and dance $(n=4)$. Other activities included art, scouting, robotics, and yearbook. We compared the 


\section{Merry J. Sleigh et al.,/2019}

demographic characteristics of the two groups responses on the importance of participation, extent (athletes and non-athletes). Chi-squares tests of identity was based on the activity, and extend that independence confirmed that the groups were self-esteem was based on the activity. The computed equivalent for participants' gender $\left[\chi^{2}(2)=2.24, p>\right.$ alpha reliability for this variable was .81 . $.05, n s]$ and race $\left[\chi^{2}(4)=5.98, p>.05, n s\right]$. An independent $t$-test confirmed that the mean age of the two groups did not significantly differ, $t(104)=$ $1.53, p=.13$.

\subsubsection{Materials \& Procedures}

Participants were tested in group settings, and the protocol received Institutional Review Board approval. The survey materials began with participants being instructed to "think only about the time period when you were in high school." They were then asked if they had participated in any type of sport. Participants who played sports were asked to indicate the one sport that was "the biggest part of your identity at the time" and "the sport in which you invested the most time and energy." Participants who indicated that they did not play a sport were asked to indicate the one activity that was "the biggest part of your identity at the time" and "the activity in which you invested the most time and energy." Athletes were told to keep their sport in mind as they responded to the survey questions, while nonathletes were told to focus on their non-sport activity. Non-athletes were told to mentally substitute wording in the scales where necessary. For example, they were told that "teammates" should refer to any peers who participate in their activity alongside them, while "coach" could be a leader or group supervisor.

Following these instructions, participants encountered a series of researcher-created questions that assessed hours per week participants invested in their activity, frequency of activity-related travel, seriousness of participation, importance of participation, amount of time spent thinking about the activity, and performance level. Responses were made on 4-point Likert scales. We also asked participants to indicate how much their identity and self-esteem during high school were based on the activity; these responses were made on 5-point Likert scales. We created an "identification with activity" score for each participant by combining the
Participants were asked to rank five factors (self-esteem, group cohesion, winning, improvement/growth, and fun) with 1 representing the factor that was most important to their coaches and 5 representing the factor that was least important to their coaches.

Next, participants responded to the same 12item Sport Engagement Scale as did the coaches, which assessed three aspects of engagement: vigor, absorption, and dedication [22]. When we modified the scale for our coaches, we asked them to respond in terms of coaching. For this sample, we referred to the high school activity and phrased statements in the past tense, asking young adults to reflect back on their high school experience. For example, an item from the original scale was "I am persistent in my sport activity" and on our modified scale was "I was persistent in my extracurricular activity." We computed an alpha reliability of .93, with sub-scales scores of .86 for vigor, .88 for dedication, and .88 for absorption.

Identical to our coach sample in Study One, our student sample responded to the 15-item Athlete Burnout Questionnaire (Raedeke \& Smith, 2001), with a calculated alpha reliability of .89 . Sub-scale scores were .77 for RA, .92 for PE, and .87 for D. Participants also responded to the high school experiences questionnaire used in Study One (Nelson et al., 2019), with alpha reliabilities for the sub-scales of .91 for positive interpersonal, .92 for negative interpersonal, .94 for positive performance, and .95 for negative performance $[20,23]$.

Next, our participants responded to the 4item Intention to Mentor scale [32]. Sample items from this scale are, "I would like to be a mentor" and "I intend to be a mentor." We modified the scale, replacing "mentor" with "sports coach." Thus, the revised statement was, "I would like to be a sports coach." Responses were made on a 7-point scale where 1 represented "Strongly disagree" and 7 represented "Strongly agree." The published reliability is .92, and we achieved a reliability of .95 . 


\section{Merry J. Sleigh et al.,/2019}

Last, participants responded to demographic identification with the activity for both athletes [ $(t=$ questions to assess age, gender, and race [32]. 4.03, $p<.001), F(1,57)=16.22, p<.001, R^{2}=.22$.] and non-athletes $[(t=2.77, p=.008), F(1,43)=$ 7.69, $\left.p=.008, R^{2}=.15\right]$. See Tables 6 and 7. We also

\subsection{Results} tested the three sub-scales of engagement,

Motivation to coach was examined using hierarchical regressions; we examined the high school athlete and non-athlete groups independently. We included identification with the activity, positive interpersonal, positive performance, negative interpersonal, and negative performance as dedication, vigor, and absorption, as predictors for motivation to coach. A motivation to coach was predicted by dedication for athletes $[(t=2.64, p=$ .01), $\left.F(1,57)=6.98, p=.011, R^{2}=.11\right]$ and nonathletes [ $(t=2.83, p=.007), F(1,45)=7.98, p=.007$, $\left.R^{2}=.15\right]$. See Tables 8 and 9 . predictors. A motivation to coach was predicted by

Table 6. Summary of Hierarchical Regression Analysis for Variables Predicting Motivation to Coach for Athletes

\begin{tabular}{|c|c|c|c|c|c|c|}
\hline Variable & $\boldsymbol{\beta}$ & $t$ & $p$ & $\mathbf{R}$ & $\mathbf{R}^{2}$ & $\Delta \mathrm{R}^{2}$ \\
\hline Step 1 & & & & .471 & .222 & .222 \\
\hline Identification with & .471 & 4.03 & .000 & & & \\
\hline Step 2 & & & & .487 & .237 & .016 \\
\hline Identification with & .442 & 3.68 & .001 & & & \\
\hline Positive interpersonal & .129 & 1.07 & .288 & & & \\
\hline Step 3 & & & & .493 & .243 & .006 \\
\hline Identification with & .409 & 3.14 & .003 & & & \\
\hline Positive interpersonal & .099 & .768 & .446 & & & \\
\hline Positive performance & .090 & .650 & .518 & & & \\
\hline Step 4 & & & & .495 & .245 & .002 \\
\hline Identification with & .420 & 3.13 & .003 & & & \\
\hline Positive interpersonal & .070 & .461 & .647 & & & \\
\hline Positive performance & .072 & .487 & .628 & & & \\
\hline Negative interpersonal & -.059 & -.382 & .704 & & & \\
\hline Step 5 & & & & .506 & .256 & .011 \\
\hline Identification with & .418 & 3.12 & .003 & & & \\
\hline Positive interpersonal & .109 & 3.12 & .493 & & & \\
\hline Positive performance & .096 & .635 & .528 & & & \\
\hline Negative interpersonal & -.143 & -.789 & .434 & & & \\
\hline Negative performance & .163 & .891 & .377 & & & \\
\hline
\end{tabular}


Table 7. Summary of Hierarchical Regression Analysis for Variables Predicting Motivation to Coach for NonAthletes

\begin{tabular}{|c|c|c|c|c|c|c|}
\hline Variable & $\beta$ & $\boldsymbol{t}$ & $p$ & $\mathbf{R}$ & $\mathbf{R}^{2}$ & $\Delta R^{2}$ \\
\hline Step 1 & & & & .390 & .152 & .152 \\
\hline Identification with & .390 & 2.77 & .008 & & & \\
\hline Step 2 & & & & .390 & .152 & .000 \\
\hline Identification with & .386 & 2.65 & .011 & & & \\
\hline Positive interpersonal & .018 & .127 & .899 & & & \\
\hline Step 3 & & & & .446 & .199 & .047 \\
\hline Identification with & .245 & 1.45 & .156 & & & \\
\hline Positive interpersonal & -.085 & -.537 & .594 & & & \\
\hline Positive performance & .288 & 1.54 & .130 & & & \\
\hline Step 4 & & & & .469 & .220 & .021 \\
\hline Identification with & .306 & 1.71 & 095 & & & \\
\hline Positive interpersonal & -.234 & -1.10 & .277 & & & \\
\hline Positive performance & .289 & 1.55 & .129 & & & \\
\hline Negative interpersonal & -.209 & -1.05 & .301 & & & \\
\hline Step 5 & & & & .495 & .245 & .025 \\
\hline Identification with & .326 & 1.82 & .076 & & & \\
\hline Positive interpersonal & -.250 & -1.18 & .246 & & & \\
\hline Positive performance & .291 & 1.57 & .125 & & & \\
\hline Negative interpersonal & -.023 & 1.57 & .931 & & & \\
\hline Negative performance & -.255 & -1.14 & .263 & & & \\
\hline
\end{tabular}

Table 8. Summary of Hierarchical Regression Analysis for Engagement Subscales Predicting Motivation to Coach for Athletes

\begin{tabular}{lcccccc}
\hline \multicolumn{1}{c}{ Variable } & $\boldsymbol{\beta}$ & $\boldsymbol{t}$ & $\boldsymbol{p}$ & $\mathbf{R}$ & $\mathbf{R}^{\mathbf{2}}$ & $\boldsymbol{\Delta} \mathbf{R}^{\mathbf{2}}$ \\
\hline Step 1 & & & & .330 & .109 & .109 \\
Dedication & .330 & 2.64 & .011 & & & \\
Step 2 & & & & .347 & .121 & .012 \\
Dedication & .238 & 1.45 & .153 & & & \\
Absorption & .142 & .863 & .392 & &
\end{tabular}


Merry J. Sleigh et al.,/2019

Step 3

Dedication

.165

.806

.424

Absorption

.110

.631

.530

Vigor

.125

.614

.542

Table 9. Summary of Hierarchical Regression Analysis for Engagement Subscales Predicting Motivation to Coach for Athletes

\begin{tabular}{lcccccc}
\hline \multicolumn{1}{c}{ Variable } & $\boldsymbol{\beta}$ & $\boldsymbol{t}$ & $\boldsymbol{p}$ & $\mathbf{R}$ & $\mathbf{R}^{\mathbf{2}}$ & $\boldsymbol{\Delta} \mathbf{R}^{\mathbf{2}}$ \\
\hline Step 1 & & & & .388 & .151 & .151 \\
Dedication & .388 & 2.83 & .007 & & & \\
Step 2 & & & & .389 & .151 & .001 \\
Dedication & .363 & 1.74 & .089 & & & \\
Absorption & .034 & .164 & .870 & & .152 & .001 \\
Step 3 & & & & .390 & \\
Dedication & .333 & 1.31 & .197 & & & \\
Absorption & .019 & .086 & .932 & & & \\
Vigor & .052 & .211 & .834 & & & \\
\hline
\end{tabular}

We compared high school athletes to nonathletes using an independent $t$-test. Our high school athletes and non-athletes shared similar levels of activity investment, as well as positive and negative high school extracurricular events. Athletes reported a stronger motivation to coach in the future than did non-athletes, $t(104)=1.92, p=.05$. The mean for athletes was $3.03(S D=1.93)$, and for non-athletes was $2.37(S D=1.56)]$. We did not find any gender differences on these variables.

We split the file and looked at athletes and non-athletes separately. The more former high school athletes wanted to coach, the more important their sport was to them $[r(59)=.38, p=.003]$, the more their self-esteem was based on the sport $[r(59)$ $=.33, p=.01]$, and the higher their self-rated performance level in high school $[r(59)=.27, p=$ .038].

The more former high school non-athletes wanted to coach, the more important their extracurricular activity was to them $[r(46)=.30, p=$ $.042]$, more their self-esteem was based on the activity $[r(47)=.43, p=.002]$, higher their self-rated performance level $[r(46)=.35, p=.019]$ and the less their high school coach/leader focused on improvement and growth $[r(46)=.29, p=.049]$.

\subsection{Discussion}

In contrast to our first hypothesis, high school experiences did not predict a desire to coach in recent high school graduates. Instead, we found support for our second hypothesis. Young adults who identified with and were dedicated to their extracurricular activity demonstrated a stronger motivation to be a coach in the future. Likely, young adults viewed coaching as a way to stay connected with an activity that was a meaningful part of their identity.

This pattern revealed by recent high school graduates was different than that which we found in our coaches in Study One, whose coaching motivation and burnout were predicted by their high school experiences. One possible explanation is that desire 


\section{Merry J. Sleigh et al.,/2019}

to coach is conceptually unique from coaching participants in extracurricular activities could be motivation and persistence, in the same way that surveyed in future studies.

planned behavior does not always result in actual behavior [33]. Graduates who had a desire to coach may not be the adults who end up becoming coaches. This possibility offers an area ripe for future research.

Alternatively, the ages of our two samples might provide further insight into these differences. Our recent high school graduates were young adults, in the midst of the developmental task of identity exploration, whereas our adult coaches were in a life stage characterized by career investment and having the accumulation of experiences needed to mentor. Therefore, it makes sense that young adults linked their future plans to their current identity, whereas our older coaches were referring to specific elements of their past experiences to inform their investment in mentoring others.

Supporting our hypothesis, we found that athletes reported a stronger motivation to coach than non-athletes. Athletes usually have coaches, whereas non-athletes may use a variety of terms to describe their leaders; thus, one possible explanation may be that athletes are more knowledgeable about what coaching entails. Another possibility, as previously mentioned, is that these athletes simply wanted an avenue to continue participation in a personally meaningful activity. The latter seems particularly likely as even non-athletes, who evaluated their high school activity as more important and connected to their self-esteem, also expressed a stronger desire to coach in the future. This motivation seems to persist over time as the vast majority of the coaches we surveyed had been high school athletes.

\section{Limitations and Future Directions}

Although the use of retrospective, self-report data is not uncommon in this domain of research our use of this methodology for our recent high school graduates could be considered a limitation [34, 35]. Even though our participants were reporting on relatively recent events, this methodology could have contributed to measurement bias. To address this concern, current high school students who are active

\section{Conclusion}

High school experiences influenced individuals' motivation to coach; however, that influence seems to depend on their stage of life. Events associated with their extracurricular activities did not influence recent graduates' desire to coach, and instead, identification with and dedication to their activities predicted their desire to coach. In contrast, adult coaches' interpersonal and performance events from high school influenced their coaching motivation, amotivation, and burnout. In other words, our adult coaches seemed to reflect on the impact of their high school experiences in a qualitatively different way than did recent graduates. Perhaps the memories of adolescent experiences were modified as individuals' gained life experience or perhaps the process of coaching encouraged individuals to reflect back on their own times of being coached from a new perspective. In sum, our findings suggests that the quality of high school extracurricular experiences has implications that extend into adulthood and add to the limited research that explores the antecedents and consequences of coach-specific motivation. 


\section{Merry J. Sleigh et al.,/2019}

\section{References}

[1] G.A. Mageau, R.J. Vallerand, The coach-athlete relationship: A motivational model, Journal of Sports Sciences, 21(2003) 883-904.

[2] N. Gillet, R.J. Vallerand, S. Amoura, B. Baldes, Influence of coaches' autonomy support on athletes' motivation and sport performance: [10] A test of the hierarchical model of intrinsic and extrinsic motivation, Psychology of Sport \& Exercise, 11(2010) 155-161.

[3] J. Mazer, K. Barnes, A. Grevious, C. Boger, Coach verbal aggression: A case study [11] examining effects on athlete motivation and perceptions of coach credibility, International Journal of Sport Communication, 6(2013) 203-213.

[4] L. Gano-Overway, M. Guivernau, Setting the [12] SCENE: Developing a caring youth sport environment, Journal of Sport Psychology in Action, 9(2018) 83-93.

[5] K. Fransen, F. Boen, M. Vansteenkiste, N. Mertens, \& G. Vande Broek, The power of [13] competence support: The impact of coaches and athlete leaders on intrinsic motivation and performance, Scandinavian Journal of Medicine \& Science in Sports, 28 (2018) 725745 .

[6] A. Van Hoye, J-P Huezé, J. Meganck, J. Seghers, \& P. Sarrazin, Coaches' and players' perceptions of health promotion activities in sports clubs, Heath Education Journal, 77(2018) 169-179.

[7] B. Reynders, M. Vansteenkiste, S. Van [15] Puyenbroeck, N. Aelterman, M. De Backer, J. Delrue, G-J De Muynck, K. Fransen, L. Haerens, G.V. Broek, Coaching the coach: Intervention effects on need-supportive coaching behavior and athlete motivation and engagement, Psychology of Sport \& Exercise, 43(2019) 288-300.

[8] Y.H. Lee, \& P. Chelladurai, Emotional intelligence, emotional labor, coach burnout, job satisfaction, and turnover intention in sport leadership, European Sport Management Quarterly, 8 (2018) 393-413.

[9] S.E. Short, M.W. Short, C.R. Haugen, The relationship between efficacy and burnout in coaches, International Journal of Coaching Science, 9(2015) 37-49.

S. Westfall, E.M. Martin, D. Gould, The association between the coach-athlete relationship and burnout among high school coaches, Journal of Sport Behavior, 41(2018) 107-126.

J.F. Guzmán, K. Kingston, C. Grijalbo, G. Solomon, Predicting coaches' adherence/dropout: A prospective study, International Journal of Sports Sciences \& Coaching, 10(2015) 353-364.

S. Alcaraz, C. Viladrich, M. Torregrosa, Y. Ramis, Club and players' pressures on the motivation, vitality, and stress of development coaches, International Journal of Sports Science \& Coaching, 10(2015) 365-378.

C. Grassman, C.C. Schermuly, D. Wach, Potential antecedents and consequences of negative effects for coaches, Coaching: An International Journal of Theory, Research \& Practice, 12 (2019) 67-88.

M. Rocchi, L.G. Pelletier, The antecedents of coaches' interpersonal behaviors: The role of the coaching context, coaches' psychological needs, and the coaches' motivation, Journal of Sport \& Exercise Psychology, 39 (2017) 366385.

K.N. McLean, C.J. Mallett, P. Newcombe, Assessing coach motivation: The development of the Coach Motivation Questionnaire (CMQ), Journal of Sport \& Exercise Psychology, 34 (2012) 184-207.

M.A. Rocchi, L.G. Pelletier, A.L. Couture, Determinants of coach motivation and autonomy supportive coaching behaviours, Psychology of Sport \& Exercise, 14 (2013) 852-859.

[17] S. Jowett, What makes coaches tick? The impact of coaches' intrinsic and extrinsic 


\section{Merry J. Sleigh et al.,/2019}

motives on their own satisfaction and that of [26] their athletes, Scandinavian Journal of Medicine \& Science in Sports, 18 (2008) 664673.

[18] H.M., Weiss, R. Cropanzano, Affective events theory: A theoretical discussion of the [27] structure, causes and consequences of affective experiences at work, Research in Organizational Behavior, 18 (1996) 1-74.

[19] R.R. Sinclair, M. Sliter, C.D. Mohr, L.E. Sears, M.N. Deese, R.R Wright, D. Cadiz, L. Jacobs, [28] Bad versus good, what matters more on the treatment floor? Relationships of positive and negative events with nurses' burnout and engagement, Research in Nursing and Health, 38(2015) 475-491.

[20] D.W. Nelson, M.J. Sleigh, A.M. Nelson, Positive and negative events predict burnout and engagement in athletes and non-athletes, The Sports Journal, (2019).

[21] A. Clopton, Where does it begin? Exploring gender differences in student-athletes' [30] perceptions of entering the coaching profession, Women in Sport \& Physical Activity Journal, 23(2015) 34-41.

[22] F. Guillen, J.R. Martinez-Alvarado, The Sport Engagement Scale: An adaptation of the Utrecht Work Engagement Scale (UWES) for the sports environment, Universitas Psychologica, 13 (2014) 975-984.

[23] T.D. Raedeke, A.L. Smith, Development and preliminary validation of an athlete burnout measure, Journal of Sport and Exercise Psychology, 23(2001) 281-306.

[24] J.W. Adie, S. Jowett, Meta-perceptions of the coach-athlete relationship, achievement goals and intrinsic motivation among sport participants, Journal of Applied Social Psychology, 40(2010) 2750-2773.

[25] A. Riley, A.L. Smith, Perceived coach-athlete and peer relationships of young athletes and self-determined motivation for sport, International Journal of Sport Psychology, 42 (2011) 115-133.
S. Jowett, N. Ntoumanis, The coach-athlete relationship questionnaire (CARTQ):development and initial validation, Scandinavian Journal of Medicine \& Science in Sports, 14(2004) 245-257.

G. Bloom, (2013) Mentoring for sport coaches. In P. Potrac, W. Gilbert, \& J. Denison (Eds.), Routledge Handbook of Sports Coaching (pp.476-485), Routledge , New York, NY.

C. Cushion, (2015) Mentoring for success in sport coaching. In F. Chambers. (Ed.), Mentoring in Physical Education and Sports Coaching (pp. 155-162), Routledge, New York, NY.

[29] R. Reeves, R.L. Jones, Comparison of student participation motivation and coaches' perceptions of such motivation in English high school sport (Reston, VA), International Council for Health, Physical Education, Recreation, Sport, and Dance, 34(1998) 46-52.

J.A. Busser, C.P. Carruthers, Youth sport volunteer coach motivation, Managing Leisure, 15(2010) 128-139.

[31] K. Fasting, T.S. Sand, \& N. Knorre, European female sports students as future coaches? European Journal for Sport and Society, 10(2013) 307-323.

[32] B. Ragins, T. Scandura, Gender differences in expected outcomes of mentoring relationships, Academy of Management Journal, 37(1994) 957-971.

[33] M.T. Kiviniemi, C.R. Brown-Kramer, Planning versus action: Different decision-making processes predict plans to change one's diet versus actual dietary behavior, Journal of Health Psychology, 20(2015) 556-568.

[34] P. Coutinho, I. Mesquita, A.M. Fonseca, J. Cote, Expertise development in volleyball: The role of early sport activities and players' age and height, Kinesiology, 47(2015) 215-225.

[35] W.D. Russell, The relationship between youth sport specialization, reasons for participation and youth sport participation motivations: A 


\section{Merry J. Sleigh et al.,/2019}

retrospective study, Journal of Sport Behavior, 37 (2014) 286-305.

\section{Funding}

This study was not funded by any grant

\section{Acknowledgements}

The authors would like to thank every participant for his effort and time.

\section{Conflict of interest \\ None of the authors have any conflicts of interest to declare.}

\section{Informed consent}

All participants gave written informed consent to participate in this study.

\section{About The License}

\section{(1) (1)}

The text of this article is licensed under a Creative Commons Attribution 4.0 International License 